The BDJ News section accepts items that include general news, latest research and diary events that interest our readers. Press releases or articles may be edited, and should include a colour photograph if possible. Please direct your correspondence to the News Editor, Arveen Bajaj at the BDJ, The Macmillan Building, 4 Crinan Street, London N19XW or by email to bdj@bda.org

\section{Dentists call for SEHD to reconsider position on dental reform}

Dentists' leaders in Scotland have today warned that some patients could lose access to NHS dentistry as a result of reforms being implemented by the Scottish Executive Health Department (SEHD). The British Dental Association is concerned that the SEHD's unwillingness to reconsider its measurement of commitment to the NHS will leave some dentists who wish to treat NHS patients unable to do so. The definition of commitment to the NHS that the Scottish Executive intends to implement will mean that unless a dentist treats a number of patients above a minimum number, they will not be considered to be committed to the NHS and will not be eligible for new allowances arising out of the Scottish Executive Health Department's Action Plan. Dentists must also treat a minimum number of adult feepaying patients to qualify.

Dr Andrew Lamb, the British Dental Association's Director for Scotland, said, 'The intransigence of the Scottish Executive threatens to jeopardise patients' access to NHS dentistry. There are many dentists, across Scotland, who are committed to their NHS patients and want to continue treating them. Sadly, the approach of the Scottish Executive will make it increasingly difficult for some of these practitioners to continue doing so. The BDA calls upon the Scottish Executive to reconsider its stance on the definition of commitment to the NHS as this will only serve to alienate a number of practitioners who would like to keep seeing NHS patients.'

\section{Good Practice Award winners}

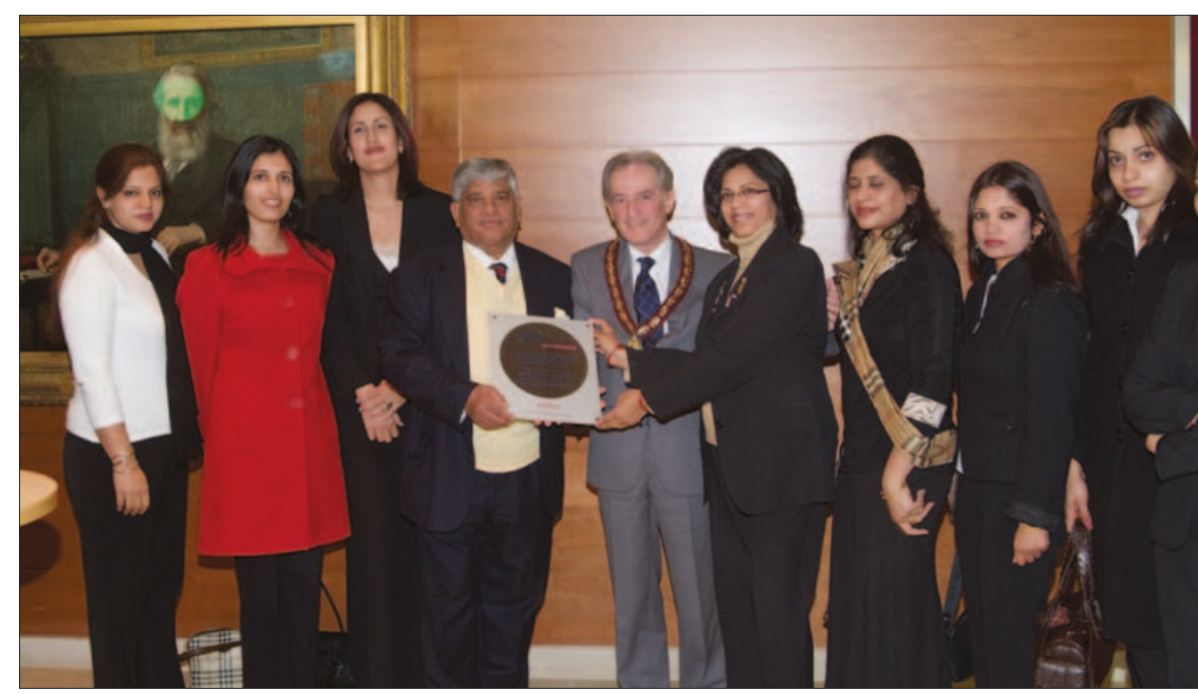

Principal Dr A. H.Ghauri, practice manager Dr Alpana Rathor and the team of Ghauri Dental Centre, Heston Branch recently received the BDA Good Practice Award from John Craig, president of the BDA.

\section{Red wine good for gums}

Good news for wine lovers: a component found in red wine can help prevent and treat periodontitis. The health benefits are believed to come from a broad range of compounds collectively known as polyphenols. Recent studies have also shown that red wine, and particularly grape seeds, possesses anti-inflammatory and anti-tumour properties. Scientists from Université Laval (Québec, Canada) conducted a study to investigate the role of polyphenols, including those from red wine, in scavenging free radicals released by immune cells stimulated with components of bacteria causing periodontal diseases. Because free-radicals are generated by immune cells during periodontitis, it is critical to keep them at low levels to maintain healthy gums. The results of the study (reported at the recent 35th Annual Meeting of the American Association for Dental Research) indicated that red wine polyphenols significantly modulate several inflammatory components released by macrophages in response to bacterial stimuli. Specifically, polyphenols efficiently scavenged and inhibited free-radical generation by host immune cells by controlling intracellular proteins involved in their release. These anti-oxidant properties of red wine polyphenols could be useful in the prevention and treatment of inflammatory periodontal diseases.

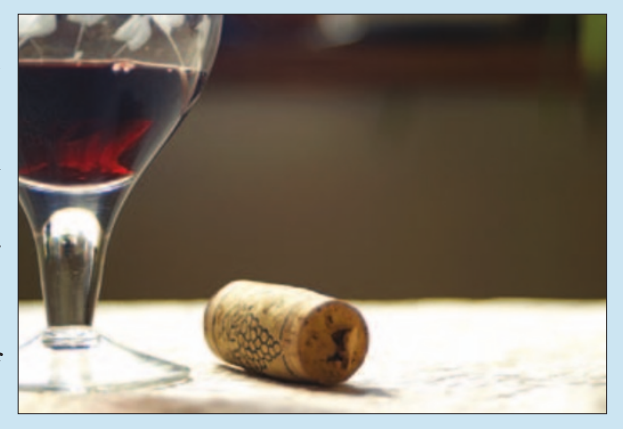




\section{DIARY}

March

Bollard MiniPlate Implant \& Distraction

Study Day

Professor Hugo De Clerck \& Dr Zvi Laster Venue: Royal Surrey County Hospital

Date: 21 March 2006

Freephone 08007833552

email sales@dbortho.com

Freefax 08007833363.

April

British Society for the Study of Prosthetic Dentistry Annual Conference

Venue: Carlton Hotel, Edinburgh

Date: 9-11 April 2006

Email:bookings@bsspd.org

www.bsspd.org

May

British Dental Conference and Exhibition Venue: International Convention Centre, Birmingham

Date: 18-20 May 2006

www.bda-events.org ( $€ 10$ discount for on-line bookings)

Registration office: 08701666625 (UK)

+44 (0) 1252771445 (overseas)

Entrance is free

10th European Congress Dentomaxillofacial radiology

Venue: Provinciehuis

Leuven, Belgium

Date: 31 May -2 June 2006

www.10ecdmfr.be

July

82nd Congress of the European Orthodontic Society

Venue: Hofburg Congress Center

Vienna, Austria

Date: 4-8 July 2006

Tel. (+43/1) 53116 - 38

Fax: $(+43 / 1) 53116-61$

e-mail: azmedinfo@media.co.at

September

FDI Annual World Dental Congress

Venue: Shenzhen, China

Date: 22-25 September 2006

www.fdiworldental.org

congress@fdiworldental.org

\section{Saliva-based oral cancer detection kit available for first time}

If oral cancer is detected early, there is an 80 to $90 \%$ chance for survival. Currently, the early detection of oral cancer depends on a thorough oral examination by a dentist or other qualified health care provider. However, scientists are working on simpler, quicker and more accurate methods for detecting oral cancer in the early stages. Saliva has recently been shown to harbour highly informative biomarkers for oral cancer detection.

Scientists in Dr David Wong's laboratory at the School of Dentistry at UCLA have discovered that seven RNAs, when found in saliva, are very useful for oral cancer detection. The saliva oral cancer RNA signature has been tested in over 300 saliva samples from oral cancer patients and healthy people, and the signature is always present in higher levels in the saliva of oral cancer patients than in saliva from healthy people, with an overall accuracy rate of about 85\%. The next important step is to turn these scientific findings into clinical tests that can be used for early oral cancer detection. At the recent 35th Annual Meeting of the American Association for Dental Research, Wong's research team reported for the first time that they have developed a standardised saliva RNA test for oral cancer ready for clinical usage.

The Saliva RNA Test has been tested in 100 oral cancer and healthy people, and it has been confirmed that four saliva oral cancer RNA biomarkers are highly accurate in detecting oral cancer, at around $82 \%$. This is the first standardised saliva-based test for clinical oral cancer detection and will have enormous clinical value in reducing the mortality and morbidity for oral cancer patients, as well as improving their quality of life.

\section{BDA reaction to Which? survey on patient access}

Which? research shows consumers are highly concerned about access to an NHS dentist and have a strong lack of trust that the Government can deliver on its promises. More than three quarters of people in England believe that it will get harder to find an NHS dentist in the next 12 months, while one in 10 think the situation will stay the same and only 3\% think it will get easier. When asked whether they trusted the Government to improve NHS dentistry over the next year almost four out of five people said no, with those respondents aged over 55 even less likely to trust them.

Reacting to the publication of the survey, Lester Ellman, Chair of the BDA's General Dental Practice Committee, said, "These findings will come as no surprise to dentists who are deeply concerned about the impact these changes will have on their patients.

The BDA has warned the Government that its plans are flawed and the way they are being introduced is creating confusion and uncertainty. We don't believe the new contract will achieve the Government's aims of securing patient access, improving oral health or raising the quality of patient care.” The Which? survey was published just days after a BDA survey of Local Dental Committees also found confusion about the forthcoming changes to NHS dentistry.

\section{Antony Townsend to leave the GDC}

The chief executive of the General Dental Council, Antony Townsend, has resigned. Antony, who has been in post for almost five years, will leave the GDC in the summer to become chief executive of the new Law Society Regulatory Body. Arrangements are being made to recruit his successor.

Antony Townsend

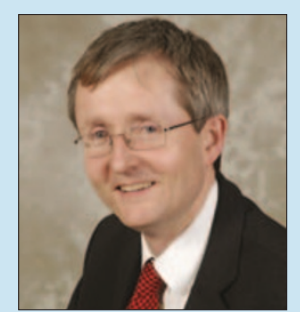




\section{Obesity and periodontal disease}

Researchers from University at Buffalo found that obesity is a significant predictor for periodontal disease, regardless of age, gender, race, ethnicity, and smoking. The study results, printed in a recent supplement to the Journal of Periodontology, suggests that insulin resistance mediates the relationship between obesity and periodontal disease. It was found that the severity of periodontal attachment loss increased proportionally with increasing insulin resistance. In addition, the number of teeth lost increased significantly with increasing levels of insulin resistance.

Individuals in the highest insulin resistance category lost 1.1 more teeth compared to individuals in the lowest category. 'People who have a higher body mass index produce cytokines (hormone-like proteins), that lead to systemic inflammation and insulin resistance, said Robert J. Genco, vice provost at the University at Buffalo and editor of the Journal of Periodontology. 'We propose that chronic stimulation and secretion of proinflammatory cytokines associated with periodontal infection also occurs, contributing to insulin resistance, which may further predispose to diabetes mellitus.' Genco and his research team recently showed that diabetics with periodontal disease may have greater mortality from diabetic complications such as cardiovascular disease and kidney complications than diabetics with little or no periodontal disease.

\section{Cigarette smoking increases risk for root canal treatment}

According to a new study appearing in the April issue of the Journal of Dental Research, cigarette smoking can more than double the risk of needing root canal treatment. 'The findings substantiate what most of us already know: smoking is detrimental to your health,' said Elizabeth Krall Kaye, a professor at Boston University's School of Dental Medicine in Boston, and the lead author of the study. 'But because root canal treatment is so common-it's estimated that half of US adults have experienced one by age 50 - I think people can relate to it more than lung cancer and other smoking-induced conditions. No matter what your age, you may need a root canal and as our research shows, smoking increases your risk.'

The findings are based on data collected during Veterans Affairs Normative Aging and Dental Longitudinal studies at the VA Boston Healthcare System in Boston. The study, which began in 1968, tracked how men's dental and physical health progressed over the course of 30 years. Men visited the study site every three years where they were checked for signs of caries, or cavities, tooth restorations and periodontal disease. Clinicians also took mouth x-rays and documented their smoking habits, including frequency and type of tobacco. From the data, the researchers were able to identify approximately 811 men with teeth that were free of root canal treatment at the study's beginning.

The researchers found that cigarette smokers are 70\% more likely to need root canal treatment than non-smokers. Besides identifying the risk for root canal treatment, the research also showed the positive effects of quitting. 'The total amount time smoked and total time they remained smoke-free was directly related to their risk,' said Dr Kaye. 'For example, the teeth of a man who smoked for less than four years had a likelihood of treatment that was 20 percent greater than that of non-smokers, but the risk doubled in men who smoked anywhere between five and 12 years and was 120 percent greater for men who smoked for more than 12 years. The good news is that after being smoke-free for nine years, the risk returned to the level of men who never smoked.'

Dr Kaye said that while the research doesn't explain why the risk is increased among cigarette smokers, they suspect that the body's reduced infection-fighting capabilities as a result of smoking may contribute. 'Other studies have also suggested that smokers experience more dental cavities, which is a major reason for root canal treatment,' said Dr Kaye. 'Hopefully future research will be able to identify the mechanisms that explain why cigarette smokers have more root canal treatments.'

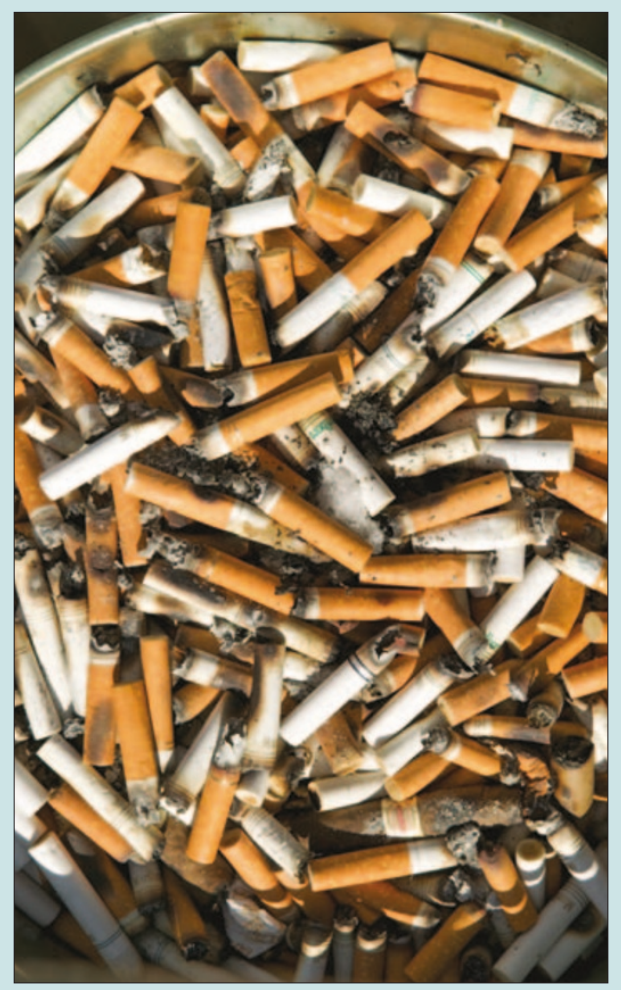

\section{Taste cell breakthrough}

Researchers from the Monell Chemical Senses Center have succeeded in growing mature taste receptor cells outside the body and for the first time have been able to successfully keep the cells alive for a prolonged period of time.

The establishment of a viable long-term model opens a range of new opportunities to increase scientists' understanding of the sense of taste and how it functions in nutrition, health and disease. 'We have an important new tool to help discover molecules that can enhance or block different kinds of tastes,' said principal investigator Nancy Rawson. 'In addition, the success of this technique may provide hope for people who have lost their sense of taste due to radiation therapy or tissue damage, who typically lose weight and become malnourished. This system gives us a way to test for drugs that can promote recovery.' The findings are reported in an online journal called Chemical Senses.

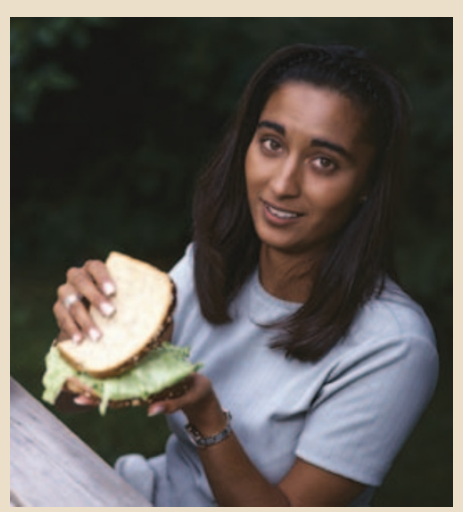




\section{GDC calls for views on fitness to practise guidance}

The General Dental Council (GDC) is developing new guidance to provide a framework for fitness to practise decision-making, and is calling for your views. The GDC is strengthening its arrangements for dealing with problems of behaviour and poor health in dental professionals, and introducing much-needed new procedures to tackle problems of professional competence. To support this new fitness to practise system, the GDC is publishing a series of guidance documents. The guidance aims to promote consistency and clarity in decision-making, and should also help the public and professionals understand why and how decisions about dental professionals' fitness to practise have been made. The GDC is now soliciting input to four draft guidance documents on:

- The Investigating Committee: case referral (the criteria for deciding which cases should be referred for full hearing before a practice committee; when to close cases at the Investigating Committee stage, and when to issue advice and warnings instead of ordering a full hearing).

- Interim suspensions and interim conditional registration (the use of interim orders pending a full practice committee hearing).

- The relationship between GDC investigation and fitness to practise procedures, and the new Dental Complaints Service (DCS) (for complaints about private dentistry).

- Guidance to case work and investigations staff on handling fitness to practise matters.

Visit the GDC website (www.gdc-uk.org) for details of the consultation. The closing date for responses is Wednesday 19 April 2006. The GDC is also currently seeking views on the draft Rules for the new fitness to practise system itself - in other words the subsidiary legislation that provides the framework for the new system. The closing date for responses to this consultation is Friday 31 March 2006.

The GDC has already consulted on and produced two other sets of fitness to practise guidance - one for the Professional Conduct Committee, and another on the effect of criminal convictions and proven misconduct on registration. The new fitness to practise system, which the new guidance documents will support, is expected to launch in July 2006.

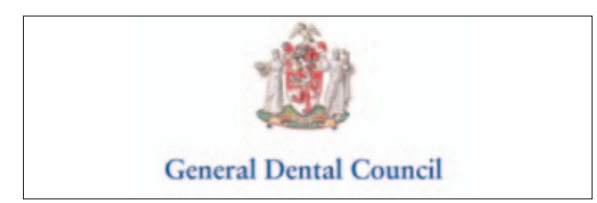

\section{$B D J$ assists with murder enquiry}

In 2001 Saraya Broadhurst went missing from her home in Torquay, Devon. On 7 November 2005, following information from local residents, an excavation was conducted at the address from which Saraya went missing. Human remains of a white female were discovered buried in the garden. Badly decomposed, the only way to identify the human remains was through dental records. The Devon and Cornwall Constabulary suspected that the remains were Saraya's but were unable to trace her dental records.

Detective Sergeant Ivor Lloyd asked the $B D J$ to put an appeal in the news pages of the journal. Within two days of publication (in December 2005), a dentist from north London contacted the enquiry team in Torquay, saying that they had Saraya's dental records. As a result Saraya was formally identified and a suspect charged. Detective Lloyd thanked the $B D J$ for their assistance with the investigation.

\section{Causal relationship between oral and cardiovascular health remains unclear}

New research is reinforcing the longstanding belief that a connection exists between periodontal disease and cardiovascular disease, but according to Moise Desvarieux, an epidemiologist at Columbia University's Mailman School of Public Health, the nature of the relationship is still unclear and patients cannot rely only on good oral hygiene as a way to reduce their risk for heart disease.

They must manage other risk factors for the disease as well. 'It appears a relationship exists, but we don't know exactly what it is and if it is a causal relationship, said Desvarieux. 'Therefore, we can't make recommendations for people with periodontal disease in respect to cardiovascular disease.' Desvarieux said that patients must manage all the risk factors associated with cardiovascular disease, including smoking, diabetes, and weight.

Most research on the relationship between oral and cardiovascular health has been specifically on the clinical level. Dentists measure for signs of periodontal disease, including gum inflammation, gum pocket depth, or spacing around each tooth and tooth-bone attachment loss and compare these data to ultrasound measurements of the carotid artery. If cholesterol or fatty build up is detected on the wall of the artery, there's a good chance the patient has atherosclerosis, a direct link to future stroke and cardiovascular disease. Desvarieux and a collaborative team including researchers from the Mailman School of Public Health, the College of Dental Medicine and neurologists at the College of Physicians \& Surgeons at Columbia University Medical Center, took this research one step further.

Speaking at a recent American Dental Association media briefing, he said: 'Our research brings in the microbiological factors that may connect the two diseases. We analysed bacterial samples from the oral cavity, three of which are specifically associated with periodontal disease. We found that those patients with one or any combination of these three bacteria also had atherosclerosis.' Desvarieux hypothesises that the atherosclerosis may be a result of bacteria from gum infection entering the bloodstream, creating inflammation in other parts of the body. However, he cautions 'Because both pieces of the puzzle were being measured simultaneously, we don't know which came first and we can't say whether the relationship is causal.' Desvarieux said that more research is needed.

\section{Chewing gum could speed recovery after colon surgery}

It is known that chewing gum is good for oral health, now a new study suggests it might even speed the return of normal bowel function after colon surgery. Researchers, from Santa Barbara Cottage Hospital, California, believe that chewing gum stimulates the same nerves as eating, thereby promoting the release of hormones that activate the gastrointestinal tract.

In a small study, published in the February edition of the journal Archives of Surgery, 34 volunteers were divided into two groups, one chewing sugarless gum three-times a day, the other not. The gum-chewing group left the hospital after an average of 4.3 days, compared with 6.8 days for the control group. 


\section{Quincentenary celebration}

The Royal College of Surgeons of Edinburgh's Faculty of Dental Surgery held its final UK quincentenary celebration for last year at Churchill College, Cambridge University. Organised by the regional adviser, Rob Chate, the event comprised a study day for 135 participants. The symposium was formally opened by the Dean, professor Jonathon Cowpe, who was led into the auditorium by piper Hugh Berry.

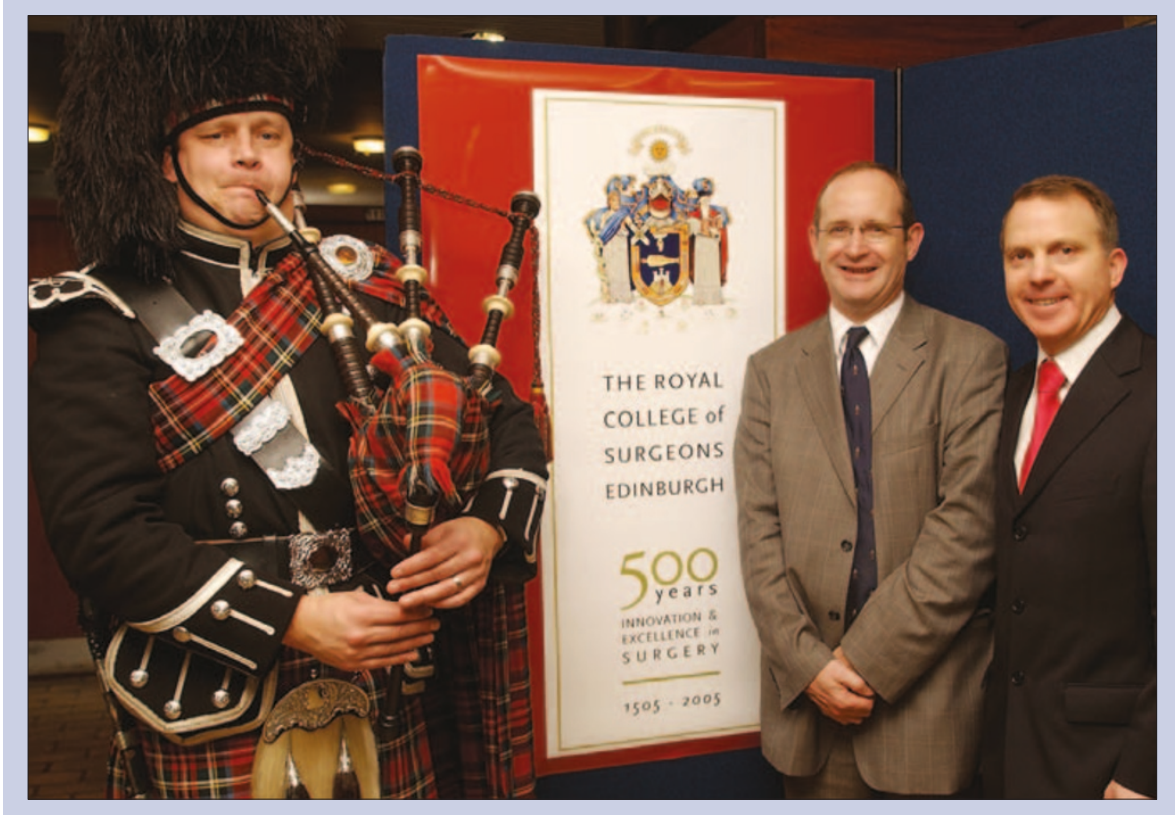

\section{Chip and pin?}

Forensic odontologists have come up with an ID chip containing personal identity information which can be placed in a tooth.

Speaking at the annual meeting of the American Academy of Forensic Sciences in Seattle, Belgian forensic odontologist Dr Thevissen reported how he and his colleagues had adapted an electronic identification tag which vets injected routinely into animals.

The researchers say that the tooth chip will be useful to forensic scientists trying to identify bodies after major incidents such as natural disasters and terrorist attacks and claim that will also have advantages over a simple identity card.

"You put your ID card in your pocket, we put it in a tooth," said Dr Thevissen, from the Catholic University of Leuvenin in Belgium. The ID chip can carry information including a person's name, nationality, date of birth, gender and national ID code and can be read after death. The idea came about because of the difficulty and expense of identifying victims of disasters from dental records. Trying to identify bodies after the Asian tsunami, for example, relied heavily on forensic dentists. But it was difficult and time consuming, particularly when teeth had been badly damaged or when dental records were not available. Similar radio frequency identification (RFID) tags are used by retailers to track stock. The tags, the size of a grain of rice, use the power from a radio pulse emitted by an electronic reader to send out a code which can be picked up. This code can be linked to a database containing a person's details or, as Dr Thevissen suggests, spell out simple information directly.

\section{BDA Benevolent Fund Winner}

The BDA Benevolent Fund congratulated WD Cummins, of Norfolk, on winning the $£ 6,000$ first prize in the BDA Benevolent Fund's Christmas Draw. The Fund offers help to dentists and their families in times of need, whether their problems are short term or demand long term assistance. Calls are made on the Fund by dentists in financial difficulty as a result of illness, stress, alcoholism, drug addiction, old age, bereavement, marriage breakdown or any of the other accidents of life. The Fund relies heavily on fundraising events like the Christmas Draw, which are vital to sustain it in its work. This year's Christmas Draw was organised by Mavis Phipps, a community dentist from Kent, and the event raised an astonishing $£ 37,200$. 